\title{
VARIATIONAL ITERATION METHOD FOR NONLINEAR OSCILLATORS WITH TWO-POINT BOUNDARY CONDITIONS
}

\author{
Naveed Anjum ${ }^{1}$ and Ji-huan $\mathrm{He}^{1}$ \\ ${ }^{1}$ Soochow University
}

May 29, 2020

\begin{abstract}
The variational iteration method, which has been considered as a powerful tool to various nonlinear oscillators with initial conditions, is extended to the case of the two-point boundary conditions. Two Lagrange multipliers have to be used in this modification, and their identification is same as that of the traditional one. A generalized equation for a class of highly nonlinear oscillators followed by three examples as special cases of this generalized equation are given to elucidate the effectivity of the method. The solution obtained from this modification not only exhibits outstanding resemblance with the results got numerically but when compared to the results obtained from other established methods it shows better accuracy as well.
\end{abstract}

\section{Hosted file}

main_manuscript_final.docx available at https://authorea.com/users/322810/articles/455294variational-iteration-method-for-nonlinear-oscillators-with-two-point-boundaryconditions 

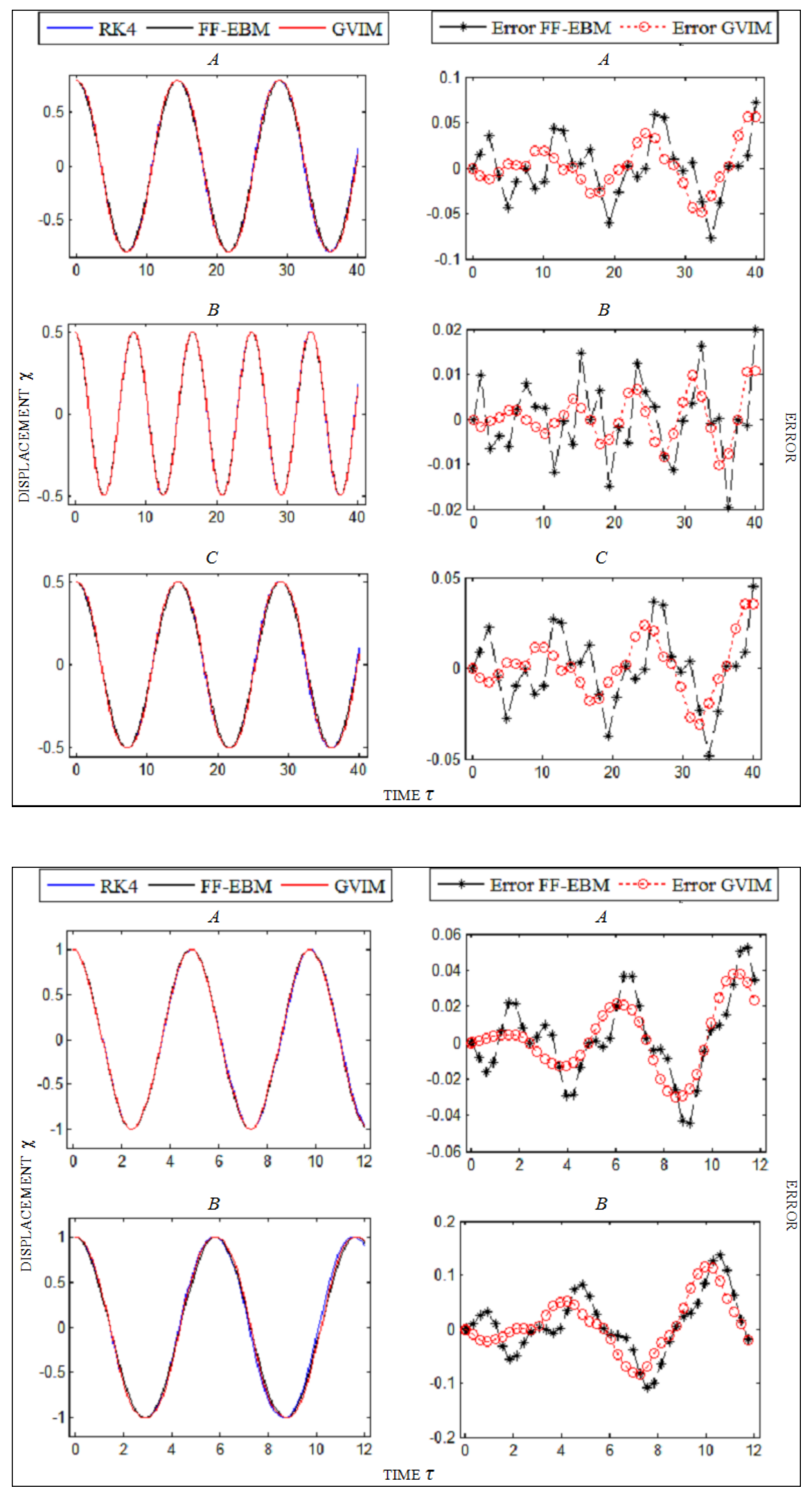


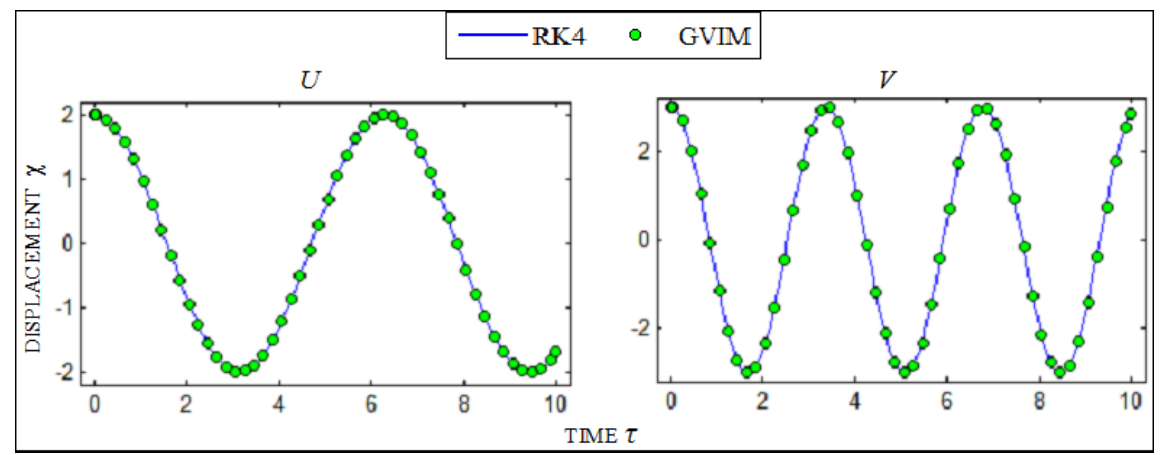

